\title{
Dynamic Hip Screw (DHS) versus Proximal Femoral Nail Anti-rotation (PFNA) Fixation for Unstable (Evans-Jensen II and III) Inter-trochanteric Fractures of Femur in Elderly
}

\author{
Manoj Kandel, ${ }^{1}$ Robin Shrestha, ${ }^{2}$ Krishna Prasad Poudel, ${ }^{1}$ Shrawan Thapa, ${ }^{1}$ Sushil Thapa, ${ }^{1}$ Sunil \\ Panta, \\ ${ }^{1}$ Department of Orthopedics, Bharatpur Hospital, Bharatpur, Chitwan, Nepal, ${ }^{2}$ Department of Orthopedics, Purbanchal \\ University Hospital, Gothgaon, Morang, Nepal.
}

\begin{abstract}
Background: Dynamic hip screw (DHS) and proximal femoral nail anti-rotation (PFNA) are the two most commonly used fixation devices for inter-trochanteric fracture of femur. However, many clinical studies have shown lack of differences in the clinical outcome consistently with between these two fixation techniques. To compare the results of dynamic hip screw (DHS) and proximal femoral nail anti-rotation (PFNA) fixation in elderly patients with unstable inter-trochanteric fractures of femur. Methods: We retrospectively reviewed patients who underwent operative management for inter- trochanteric fractures of femur in our hospital between February 2013 and September 2017. Elderly patients (Age >60yrs) with unstable inter-trochanteric fracture of femur treated either with DHS fixation or with PFNA fixation were included and divided into two groups: DHS fixation group and PFNA fixation group. The comparative statistical analysis was done between two group using following parameters: average length of the incision, operation time, blood loss, fracture healing time, and degree of postoperative functional recovery. Results: The mean follow-up period, in DHS fixation group was 16 month (range 12 to 24 months) and in PFNA fixation group was 14 months (range 12 to 18 months). The differences between two groups regarding average length of the incision, operation time, and blood loss were statistically significant $(\mathrm{p}<0.05)$ and better in PFNA group whereas the differences between two groups regarding fracture healing time and the degree of postoperative functional recovery were not statistically significant $(p>0.05)$. Conclusions: PFNA fixation may be better than DHS fixation for the treatment of unstable inter-trochanteric fractures of the femur in the elderly. However, the application and usage of DHS fixation could not be neglected and the choice of treatment depends upon the systemic condition and socioeconomic status of the patient, patient's preferences, surgeon's experience and availability of treatment facility.
\end{abstract}

Keywords: inter-trochanteric femur fracture; dynamic hip screw; proximal femoral nail anti- rotation

\section{INTRODUCTION}

Inter-trochanteric fracture of the femur is common among elderly patients and often occurs following low energy trauma (e.g. fall injury). Early operative management, using implants that provide adequate fracture stabilization, is required to allow early patient mobilization and reduce morbidity associated with these fractures. Several techniques and implants have been described over the years, yet only few have yielded entirely satisfactory outcomes. ${ }^{1,2}$ Dynamic hip screw (DHS) and proximal femoral nail anti-rotation (PFNA) are the two most commonly used fixation devices for intertrochanteric fracture of femur.

DHS has been used successfully over longer period of time and has shown better fracture fixation and ability to stimulate callus formation. ${ }^{3-5}$ However, some mechanical and technical failures have been reported, when it is used for unstable intertrochanteric fractures. ${ }^{6,7}$ Moreover, it requires extensive surgical dissection and longer hospital stay. In contrast, PFNA is minimally invasive fixation device with superior biomechanics. ${ }^{8-11}$ Although many comparative studies have concluded the superiority of PFNA over DHS for inter-trochanteric fracture fixation some complications such as femoral head perforation and "cut through" have been reported with this technique. ${ }^{11-13}$ However, the differences in outcomes were not statistically significant in most of the studies. In addition, recent meta-analysis regarding fracture fixation methods for intertrochanteric fracture of femur has also failed to clarify the relative superiority of PFNA over DHS as most studies are affected with small sample size and varying fracture types. ${ }^{14-16}$ Literature still

Correspondence: Dr. Manoj Kandel, Department of Orthopaedics, Bharatpur Hospital, Bharatpur, Chitwan, Nepal. Email: manojkandel17@gmail.com. Phone: +977-9845050040. Article received: 2018-12-10. Article accepted: 2019-07-24. 
Kandel et al. Dynamic Hip Screw (DHS) versus Proximal Femoral Nail Anti-rotation..

lacks enough evidence to clarify the exact difference between these two reliable fixation methods. Therefore, this study presents our experience in treating unstable inter-trochanteric fracture of femur in the elderly using DHS and PFNA fixation devices. This study also aims to analyze the differences between these two fixation devices using following parameters: incision length, intraoperative blood loss, operation time, duration of hospital stay, fracture healing time and postoperative functional recovery.

\section{METHODS}

Retrospective analysis of the patients who underwent operative management for intertrochanteric fractures of femur in our hospital between February 2013 and September 2017 was done. Elderly patients (Age $>60 \mathrm{yrs}$ ) with unstable inter-trochanteric fracture of femur treated either with DHS fixation or with PFNA fixation were included and divided into two groups: DHS fixation group and PFNA fixation group. For each of the patients included in the study, following data was collected demographic characteristics (age, sex), fracture type (Evans- Jensen classification), incision length, operation time, blood loss, postoperative complications, duration of hospital stay, duration of follow-up and follow-up data providing information regarding fracture healing time and hip function (Harris score). All operations were performed after obtaining written informed consent. Out of 180 patients, 17 patients were operated under general anesthesia while 163 patients were operated under spinal anesthesia. All the patients were given Inj. Ceftriaxone $1 \mathrm{gm}$ at the start of operation and continued for three post op days. Analgesics and other supportive therapy, including adequate oxygen therapy, functional lung exercises and anti-osteoporosis medications ${ }^{17}$ were also started. Patients were advised for ambulation as early as $2^{\text {nd }}$ post op day with the help of walker. Isometric hamstring, quadricep, gluteii, adductor and abductor exercises were also started from $2^{\text {nd }}$ post op day. Two groups were compared using following variables: incision length, operation time, blood loss, duration of hospital stay, fracture healing time and degree of postoperative functional recovery. The statistical analysis was done using standard statistical software SPSS 15.1. The level of confidence was set on 0.05 .

\section{RESULTS}

A total of 180 patients, including 110 men and 70 women, were included in the study. Out of 180 patients DHS fixation group included 94 patients whereas PFNA fixation group included 86 patients. Average age of the patients was 73 years (range 64 to 82 years) in DHS fixation group and 76 years (range 61 to 86 years) in PFNA fixation group (Table 1).

\begin{tabular}{|c|c|c|}
\hline & PFNA group & DHS group \\
\hline \multicolumn{3}{|l|}{ Sex } \\
\hline Male & $48(56 \%)$ & $54(57 \%)$ \\
\hline Female & $38(44 \%)$ & $40(43 \%)$ \\
\hline \multicolumn{3}{|c|}{ Side of fracture } \\
\hline Right & $64(74 \%)$ & $66(70 \%)$ \\
\hline Left & $22(26 \%)$ & $38(30 \%)$ \\
\hline \multicolumn{3}{|c|}{ Evans-Jensen classification } \\
\hline I & - & - \\
\hline II & $65(77 \%)$ & $58(62 \%)$ \\
\hline III & $21(23 \%)$ & $36(38 \%)$ \\
\hline
\end{tabular}

The mean follow-up period, in DHS fixation group was 16 month (range 12 to 24 months) and in PFNA fixation group was 14 months (range 12 to 18 months). Average duration of hospital stay was 14.56 days (range 9 to 28 days) in PFNA fixation group and 16.43 days (range 13 to 31 days) in DHS fixation group, but the difference was not statistically significant $(\mathrm{p}>0.05)$ (Table 2$)$.

\begin{tabular}{|lccc|}
\hline Table 2. Comparison between two fixation devices. \\
\hline Variables & $\begin{array}{c}\text { PFNA } \\
\text { group }\end{array}$ & DHS group & p value \\
$\begin{array}{l}\text { Operation time } \\
\text { (minutes) }\end{array}$ & $\begin{array}{c}9.38(75- \\
140)\end{array}$ & $\begin{array}{c}56.30(42- \\
95)\end{array}$ & $\mathrm{p}<0.05$ \\
$\begin{array}{l}\text { Incision length(cm) } \\
\text { Intraoperative }\end{array}$ & $4(3$ to 5) & $11.5(9-16)$ & $\mathrm{p}<0.05$ \\
blood loss (ml) & $75(20-150)$ & $\begin{array}{c}429(200- \\
800)\end{array}$ & $\mathrm{p}<0.05$ \\
$\begin{array}{l}\text { Follow-up duration } \\
\text { (months) }\end{array}$ & $14(12-18)$ & $16(12-24)$ & $\begin{array}{c}\text { Non } \\
\text { specific }\end{array}$ \\
\hline
\end{tabular}

Postoperative complications following fixations have been presented in the table 3. There were no occurrences of bedsores, implant breakdown, perforation of femoral head and nonunion in any cases. The overall complication rate showed no significant difference in both the groups $(p>0.05)$ (Table 3).

\begin{tabular}{|llll|}
\hline Table 3. Post-operative complications. & \\
\hline $\begin{array}{l}\text { Complications PFNA group } \\
\text { Urinary tract } \\
\text { infection }\end{array}$ & DHS group & P-value \\
$\begin{array}{l}\text { Respiratory } \\
\text { tract infection } 5(5.8)\end{array}$ & $4(4.2)$ & \\
$\begin{array}{l}\text { Deep vein } \\
\text { thrombosis }\end{array}$ & $5(5.8)$ & $6(6.3)$ & \\
$\begin{array}{l}\text { Malunion } \\
\text { Total }\end{array}$ & $3(3.4)$ & $6(6.3)$ & \\
\hline
\end{tabular}

There was no significant difference $(p>0.05)$ in fracture healing time in both the groups. Fracture healing time ranged from 3 to 6 months, average 5 months. The results were evaluated according to Harris hip score at 12 th months. The excellent and good outcome in DHS fixation group was $89 \%$ whereas the excellent and good outcome in PFNA group was $86 \%$, but the difference in postoperative hip function was not statistically significant $(\mathrm{p}>0.05)$ (Table 4). 
Kandel et al. Dynamic Hip Screw (DHS) versus Proximal Femoral Nail Anti-rotation..

\begin{tabular}{|llll|}
\hline \hline \multicolumn{2}{|l|}{$\begin{array}{l}\text { Table 4. Post-operative hip function at } \\
\text { (Harris score). }\end{array}$} & months \\
\hline Harris Score & $\begin{array}{l}\text { PFNA group } \\
(\mathbf{n}=\mathbf{8 6})\end{array}$ & $\begin{array}{l}\text { DHS group } \\
(\mathbf{n}=\mathbf{9 4})\end{array}$ & p value \\
Excellent & $61(65)$ & $57(66)$ & \\
Good & $20(21)$ & $19(23)$ & $\mathbf{p}>\mathbf{0 . 0 5}$ \\
Fair & $13(14)$ & $10(11)$ & \\
Poor & 0 & 0 & \\
\hline
\end{tabular}

\section{DISCUSSION}

Operative fixation techniques have overcome traditional conservative management, because early operative management will reduce the period of immobilization and provide early recovery. ${ }^{1}$ However, correct patient selection and timely operation is the key for successful outcome. It is now agreed that the treatment principle of inter-trochanteric femur fractures among pre-injury ambulatory patients include rigid internal fixation and early postoperative physical activity. ${ }^{18,19}$

Currently, there are two preferred implants for inter-trochanteric femur fracture fixation: extramedullary nails (e.g. DHS) and intramedullary nails (e.g. PFNA). Dynamic hip screws (DHS), as extramedullary fixation method, have been recognized as "gold standard" for the treatment of inter trochanteric femur fractures since the beginning of its usage ${ }^{3-5}$ However, it is also accepted that this fixation device have shown technical and mechanical failure when used for unstable fractures. In contrast,

\section{REFERENCES}

1. Cole PA, Bhandari M. What's new inorthopaedictrauma. J Bone Joint Surg Am. 2005;138 87: 2823-38.

2. Horowitz BG.Retrospective analysis of hip fractures. SurgGye Obs. 1966;123:565-70.

3. Regazzoni P,Winquist R. The dynamic hip serew implant system. New York: Springer; 1985.

4. Mohan R, Karthikeyan R, Sonanis SV.Dynamic hip screw:does side make a difference ? Effects of clockwise torque on right and left DHS. Injury. 2000;31(9):697-9.

5. Chirodian N, Arch B, Parker MJ et al. Sliding hip screw fixation of trochanteric hip fractures :Outcome of 1024 procedures. Injury. 2005;36:793-800.

6. Krischak GD, Augat P, Beck A, et al. Biomechanical comparison of two side plate fixation techniques in an unstableintertrochanteric osteotomy model:sliding hip screw and percutaneous compression plate. ClinBiomech. 2007;22(10):1112-8.

7. Rokito AS, Koval KJ, Zuckerman JD.Technical pitfalls in the use of the sliding hip screw for fixation of inter-trochanteric hip fractures. ContempOrthop. 1993;26:349-56.

8. Kuzyk PR, Guy P, Kreder HJ, et al. Minimally invasive hip fracture surgery: are outcomes
PFNA fixation device have evolved as excellent tool for managing wide variety of inter-trochanteric fracture. This technique follows the principles of minimally invasive technique and effectively avoids extensive periosteal stripping. Some clinical and biomechanical studies have proved its mechanical superiority. However, this device requires multiple intra- operative $\mathrm{x}$-ray exposures and is technically challenging. In addition, many randomized clinical trials, retrospective comparative case series, and meta-analysis could not outline the strong differentiation between these two fixation devices. ${ }^{14-16}$

\section{CONCLUSIONS}

Hence, this study showed patients in PFNA fixation group had shorter duration of operation, lower amount of blood loss and earlier postoperative recovery compared to those in DHS fixation group. These outcomes were similar to outcomes reported previously. ${ }^{3-5,8-11}$ However, our observation showed no significant difference in postoperative complications and hip functions among both the groups. Therefore, PFNA fixation may be slightly better than DHS fixation for unstable inter- trochanteric fractures. Further studies with large samples and controlled trials are needed to substantiate it further

\section{Conflict of interest: None}

\section{Source of Funding: Self}

better? Orthop Trauma. 2009;23:447-53.

9. Simmermacher RK, Ljungqvist J, Bail H, et al. The new proximal femoral nail anti-rotation (PFNA) in daily practice: results of a multicentre clinical study. Injury. 2008;39 (8):932-9.

10. $\mathrm{Pu} \mathrm{JS}$, Liu L,Wang GL, et al.Results of the proximal femoral nail anti-rotation (PFNA) in elderly Chinese patients. IntOrthop. 2009;33 (5):1441-4.

11. Kuzyk PR, Lobo J, Whelan D, et al. Biomechanical evaluation of extramedullary versus intramedullary fixation for reverse obliquity inter-trochanteric fractures. J Orthop 162 Trauma. 2009;23:31-8

12. Frei HC, Hotz T, Cadosch D, et al.Central head perforation, or"cut through, "caused by the helical blade of the proximal femoral nail antirotation. J Orthop Trauma. 2012;26(8):102-7.

13. Sadowski C, Lübbeke A, Saudan M, etal.Treatment of reverse oblique and transverse inter- trochanteric fractures with use of an intramedullary nail or a 95 degrees screw-plate: a prospective, randomized study. J Bone Joint Surg Am. 2002;84(3):372-81.

14. Parker MJ, Handoll HH. Gamma and other cephalocondylic intramedullary nails versus extramedullary implants for extracapsular hip fractures in adults. Cochrane Database 


$$
\text { Syst Rev. 2010;9:CD000093. }
$$

15. Anglen JO, Weinstein JN. Nail or plate fixation of inter-trochanteric hip fractures: changing pattern of practice. A review of the American Board of Orthopaedic Surgery Database. J Bone Joint Surg Am. 2008;90:700-7.

16. Liu M,Yang Z, Pei F, et al.A meta-analysis of the Gamma nail and dynamic hip screw in treating peritrochanteric fractures. IntOrthop. 2010;34:323-8.

17. Moroni A, Faldini C, Hoang-Kim A, et al. Alendronate improves screw fixation in 183 osteoporotic bone. J Bone Joint
SurgAm.2007;89:96-101.

18. Yang E, Qureshi S, Trokhan S,et al. Gotfried percutaneous compression plating compared with sliding hip screw fixation of intertrochanteric hip fractures: a prospective randomized study. J Bone Joint Surg Am. 2011;93:942-7.

19. Dec J, Gazdzik TS, Wojcik B. Intertrochanteric fractures of the hip treated with dynamic hip screws (DHS). ChirNarzadowRuchuOrthop Pol. 2001;167-71.

Citation: Kandel M, Shrestha R, Poudel KP, Thapa S, Thapa S, Panta S. Dynamic Hip Screw (DHS) versus Proximal Femoral Nail Anti-rotation (PFNA) Fixation for Unstable (Evans-Jensen II and III) Intertrochanteric Fractures of Femur in Elderly. JCMS Nepal. 2019; 15(3):222-5. 